\title{
Mg-Al Mixed Oxide Derived from Hydrotalcites Prepared Using the Solvent-free Method: A Stable Acid-base Bifunctional Catalyst for Continuous-Flow Transesterification of Dimethyl carbonate and Ethanol
}

Hefang Wang *, Wenrui Liu, Yiyan Wang, Ning Tao, Huanhuan Cai, Jidong Liu * and Jianhua Lv*

School of Chemical Engineering and Technology, Hebei University of Technology, Tianjin, 300130, PR China

* Corresponding authors: Hefang Wang, E-mail: whf0618@163.com; Jidong Liu, E-mail: 11jjdd@163.com; Jianhua Lv, E-mail: ctstljh@hebut.edu.cn; 


\section{Contents:}

Table S1. Elemental compositions of the CHT-2-SF.

Table S2. Textural and physicochemical properties of the fresh and used CHT-2-SF.

Table S3. Acid and base properties of the fresh and used CHT-2-SF.

Figure S1. XPS wide scan spectra of CHT-2-SF.

Figure S2. The relationship between the conversion of $\mathrm{C}_{2} \mathrm{H}_{5} \mathrm{OH}$ and (A) the medium acid site $\left(A_{M}\right)$, (B) weak basic site $\left(B_{W}\right)$ and $(\mathbf{C})$ strong basic site $\left(B_{S}\right)$; the relationship between the selectivity to EMC and (D) the weak acid site $\left(A_{W}\right),(\mathbf{E})$ medium acid site $\left(\mathrm{A}_{\mathrm{M}}\right),(\mathbf{F})$ weak basic site $\left(\mathrm{B}_{\mathrm{W}}\right),(\mathbf{G})$ medium basic site $\left(\mathrm{B}_{\mathrm{M}}\right)$ and $(\mathbf{H})$ strong basic site $\left(\mathrm{B}_{\mathrm{S}}\right)$ over CHT-2-SF. Reaction condition: $\mathrm{T}=85^{\circ} \mathrm{C}, \mathrm{C}_{2} \mathrm{H}_{5} \mathrm{OH}: \mathrm{DMC}=0.8: 1, \mathrm{LHSV}=2.4 \mathrm{~h}^{-1}$. Figure S3. The relationship between the selectivity to DEC and (A) the weak acid site $\left(A_{W}\right),(\mathbf{B})$ medium acid site $\left(A_{M}\right),(\mathbf{C})$ weak basic site $\left(B_{W}\right),(D)$ medium basic site $\left(B_{M}\right)$ and $(\mathbf{E})$ strong basic site $\left(\mathrm{B}_{\mathrm{S}}\right)$ over CHT-2-SF. Reaction condition: $\mathrm{T}=85{ }^{\circ} \mathrm{C}$, $\mathrm{C}_{2} \mathrm{H}_{5} \mathrm{OH}: \mathrm{DMC}=0.8: 1, \mathrm{LHSV}=2.4 \mathrm{~h}^{-1}$.

Figure S4. Effect of molar ratio on the EMC synthesis over CHT-2-SF catalyst $(\mathrm{T}=85$ $\left.{ }^{\circ} \mathrm{C}, \operatorname{LHSV}=2.4 \mathrm{~h}^{-1}\right)$.

Figure S5. $\mathrm{N}_{2}$ adsorption-desorption isotherms of fresh and used CHT-2-SF sample.

Figure S6. XRD patterns of fresh and used CHT-2-SF sample.

Figure S7. SEM images of (A) fresh and (B) used CHT-2-SF sample.

Figure S8. $\mathrm{NH}_{3}-\mathrm{TPD}(\mathrm{A})$ and $\mathrm{CO}_{2}$-TPD (B) of fresh and used CHT-2-SF sample. 
Table S1. Elemental compositions of the CHT-2-SF.

\begin{tabular}{ccccc}
\hline Sample & $\mathrm{Mg}(\%)$ & $\mathrm{Al}(\%)$ & $\mathrm{O}(\%)$ & $\mathrm{Mg} / \mathrm{Al}$ \\
\hline CHT-2-SF & 33.68 & 15.63 & 50.69 & 2.15 \\
\hline
\end{tabular}

Table S2. Textural and physicochemical properties of the fresh and used CHT-2-SF.

\begin{tabular}{cccc}
\hline Sample & S & Pore size $(\mathrm{nm})$ & Pore volume $\left(\mathrm{cm}^{2} \cdot \mathrm{g}^{-1}\right)$ \\
\hline Fresh CHT-2-SF & 239.0 & 0.42 & 16.45 \\
Used CHT-2-SF & 203.8 & 0.35 & 16.44 \\
\hline
\end{tabular}

Table S3. Acid and base properties of the fresh and used CHT-2-SF.

\begin{tabular}{|c|c|c|c|c|c|c|c|}
\hline \multirow{2}{*}{ Catalyst } & \multicolumn{3}{|c|}{ Acid sites $(\mathrm{mmol} / \mathrm{g})$} & \multicolumn{4}{|c|}{ Base sites (mmol/g) } \\
\hline & $\mathrm{Aw}_{w^{\mathrm{a}}}$ & $\mathrm{A}_{\mathrm{M}^{\mathrm{a}}}$ & $\mathrm{A}_{\text {TOTAL }}{ }^{\mathrm{b}}$ & $\mathrm{B}_{\mathrm{W}}^{\mathrm{c}}$ & $\mathrm{B}_{\mathrm{M}^{\mathrm{c}}}$ & $\mathrm{B}_{S^{c}}$ & $\mathrm{~B}_{\text {TOTAL }^{b}}{ }^{\mathrm{b}}$ \\
\hline Fresh CHT-2-SF & 0.772 & 0.091 & 0.863 & 0.365 & 0.977 & 0.481 & 1.823 \\
\hline Used CHT-2-SF & 0.665 & 0.110 & 0.775 & 0.420 & 0.949 & 0.256 & 1.625 \\
\hline
\end{tabular}




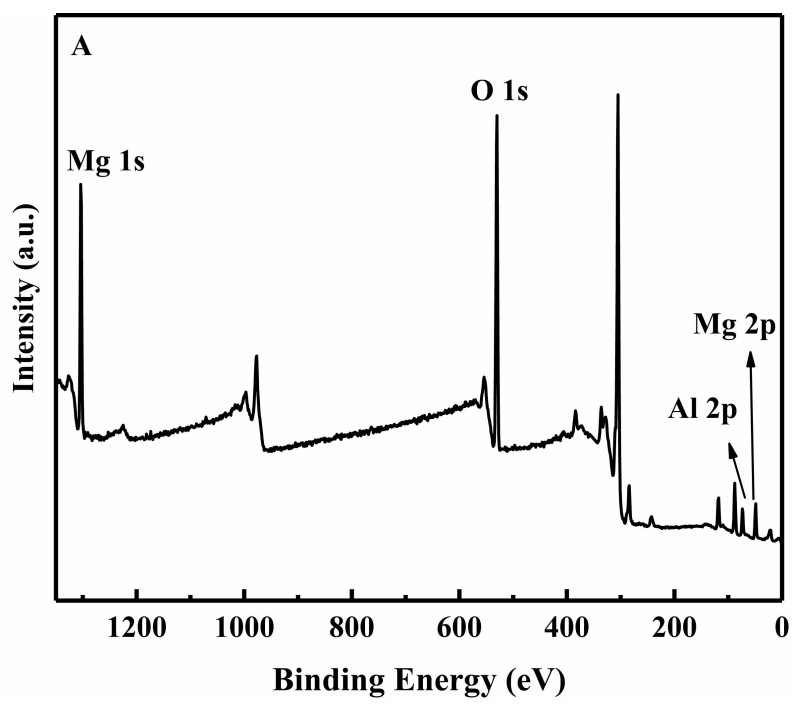

Figure S1. XPS wide scan spectra of CHT-2-SF.
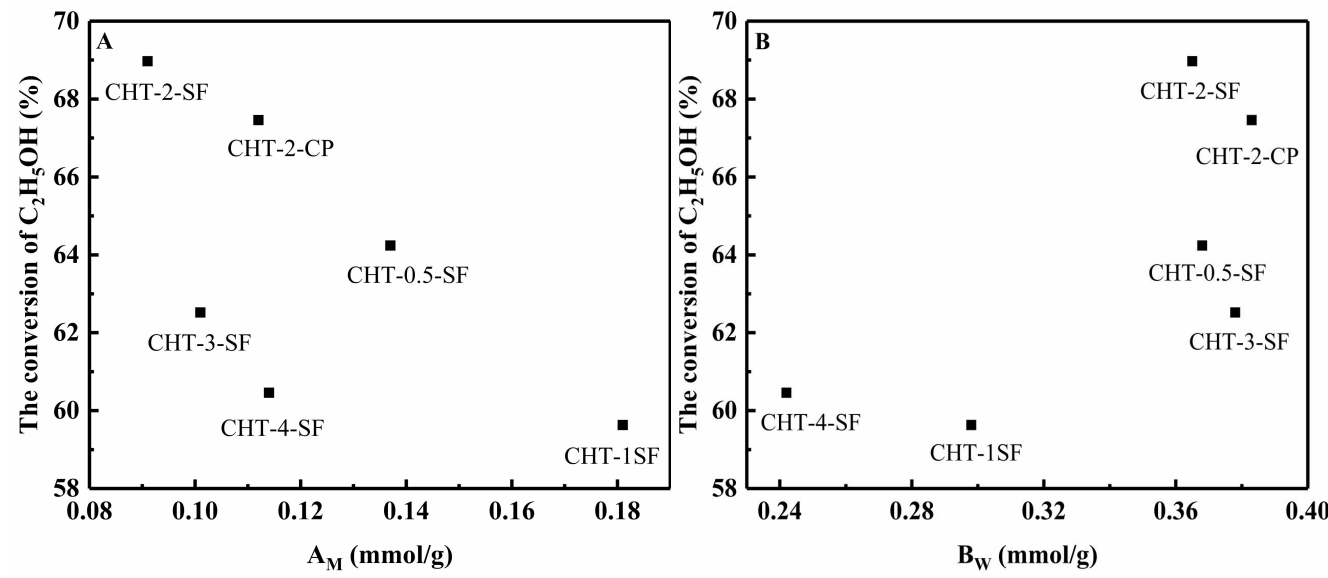

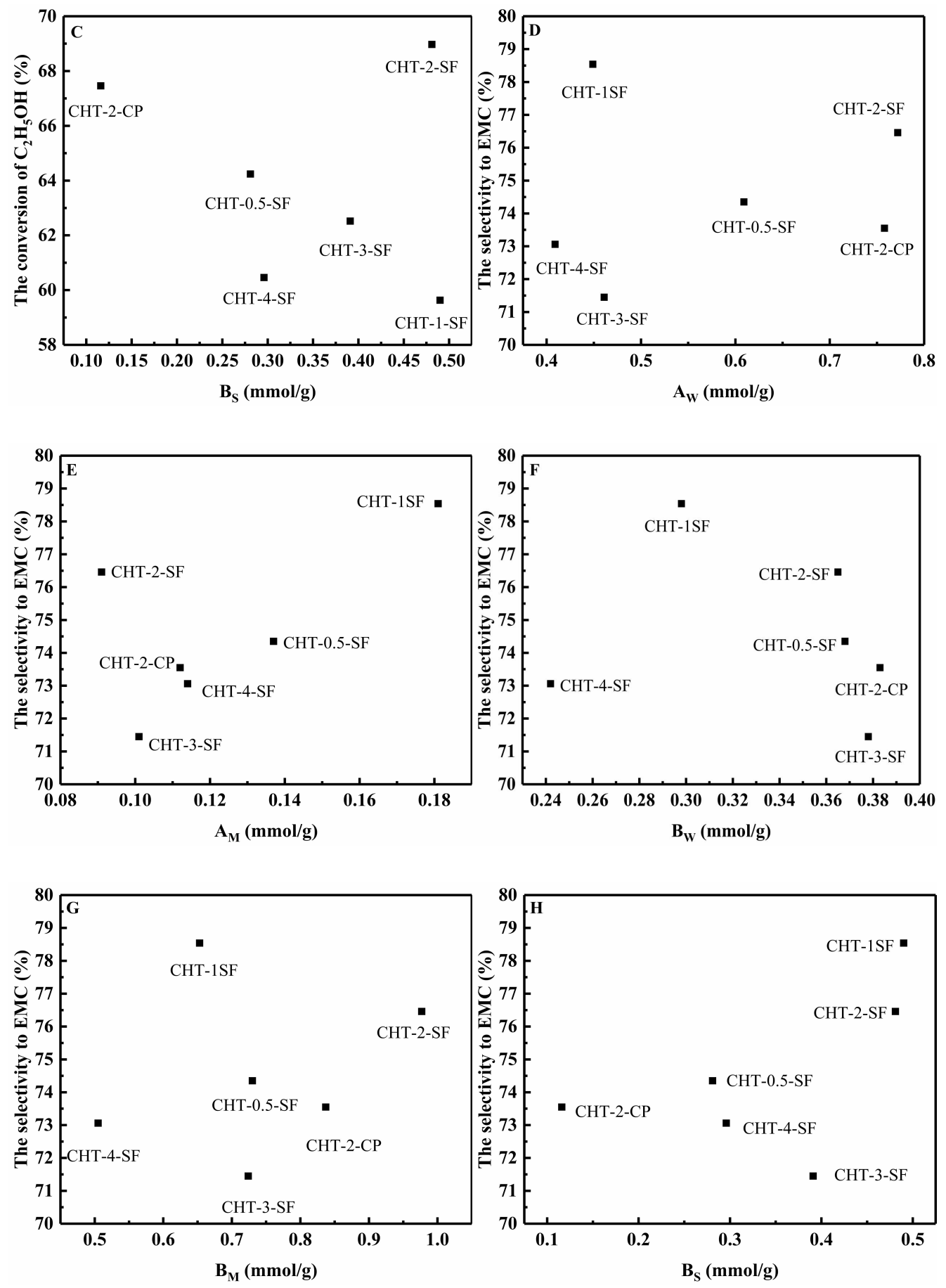

Figure S2. The relationship between the conversion of $\mathrm{C}_{2} \mathrm{H}_{5} \mathrm{OH}$ and (A) the medium acid site $\left(\mathrm{A}_{\mathrm{M}}\right)$, (B) weak basic site $\left(\mathrm{B}_{\mathrm{W}}\right)$ and $(\mathbf{C})$ strong basic site $\left(\mathrm{B}_{\mathrm{S}}\right)$; the relationship between the selectivity to EMC and (D) the weak acid site $\left(\mathrm{A}_{\mathrm{W}}\right),(\mathbf{E})$ medium acid site $\left(\mathrm{A}_{\mathrm{M}}\right),(\mathbf{F})$ weak basic site $\left(\mathrm{B}_{\mathrm{W}}\right),(\mathbf{G})$ medium basic site $\left(\mathrm{B}_{\mathrm{M}}\right)$ and $(\mathbf{H})$ strong basic site $\left(\mathrm{B}_{\mathrm{S}}\right)$ over CHT-2-SF. Reaction condition: $\mathrm{T}=85^{\circ} \mathrm{C}$, $\mathrm{C}_{2} \mathrm{H}_{5} \mathrm{OH}: \mathrm{DMC}=0.8: 1, \mathrm{LHSV}=2.4 \mathrm{~h}^{-1}$. 

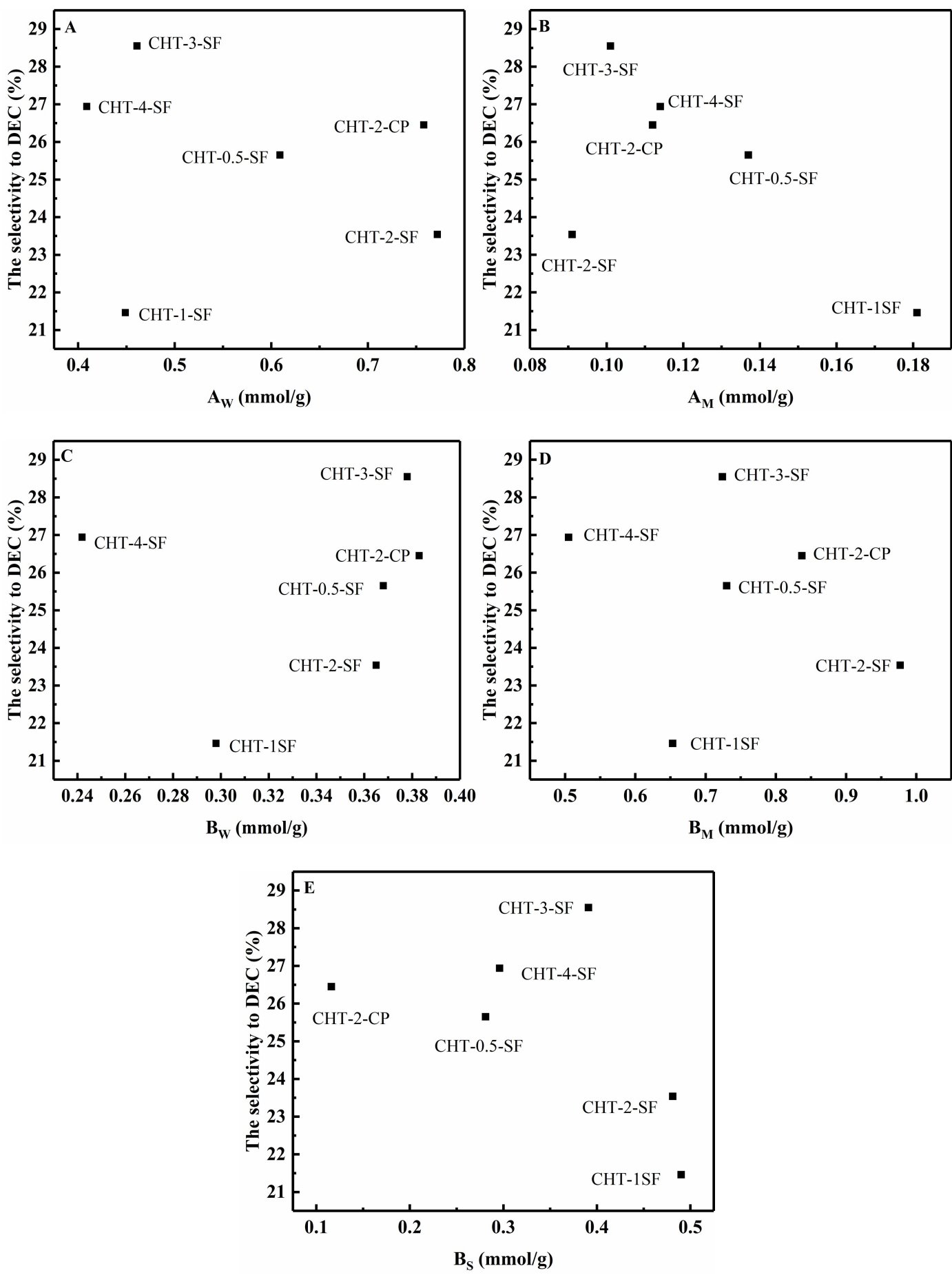

Figure S3. The relationship between the selectivity to DEC and (A) the weak acid site $\left(\mathrm{A}_{\mathrm{W}}\right),(\mathbf{B})$ medium acid site $\left(\mathrm{A}_{\mathrm{M}}\right),(\mathbf{C})$ weak basic site $\left(\mathrm{B}_{\mathrm{W}}\right),(\mathbf{D})$ medium basic site $\left(\mathrm{B}_{\mathrm{M}}\right)$ and $(\mathbf{E})$ strong basic site (BS) over CHT-2-SF. Reaction condition: $\mathrm{T}=85^{\circ} \mathrm{C}, \mathrm{C}_{2} \mathrm{H}_{5} \mathrm{OH}: \mathrm{DMC}=0.8: 1, \mathrm{LHSV}=2.4 \mathrm{~h}^{-1}$. 


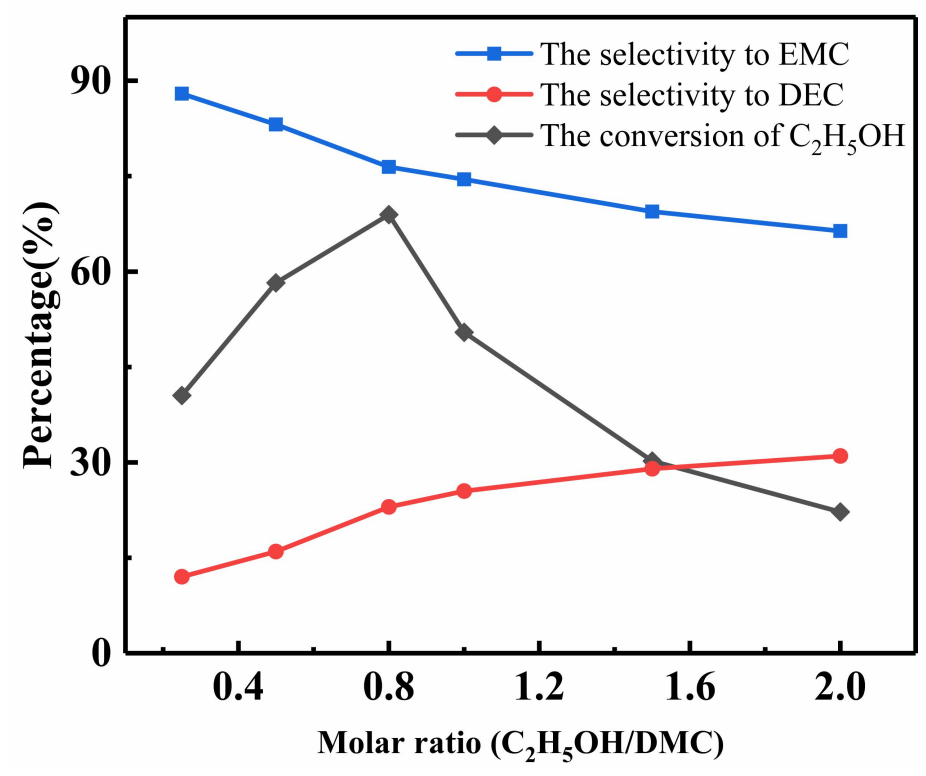

Figure S4. Effect of molar ratio on the EMC synthesis over CHT-2-SF catalyst $\left(\mathrm{T}=85^{\circ} \mathrm{C}\right.$, LHSV $=$ $\left.2.4 \mathrm{~h}^{-1}\right)$.

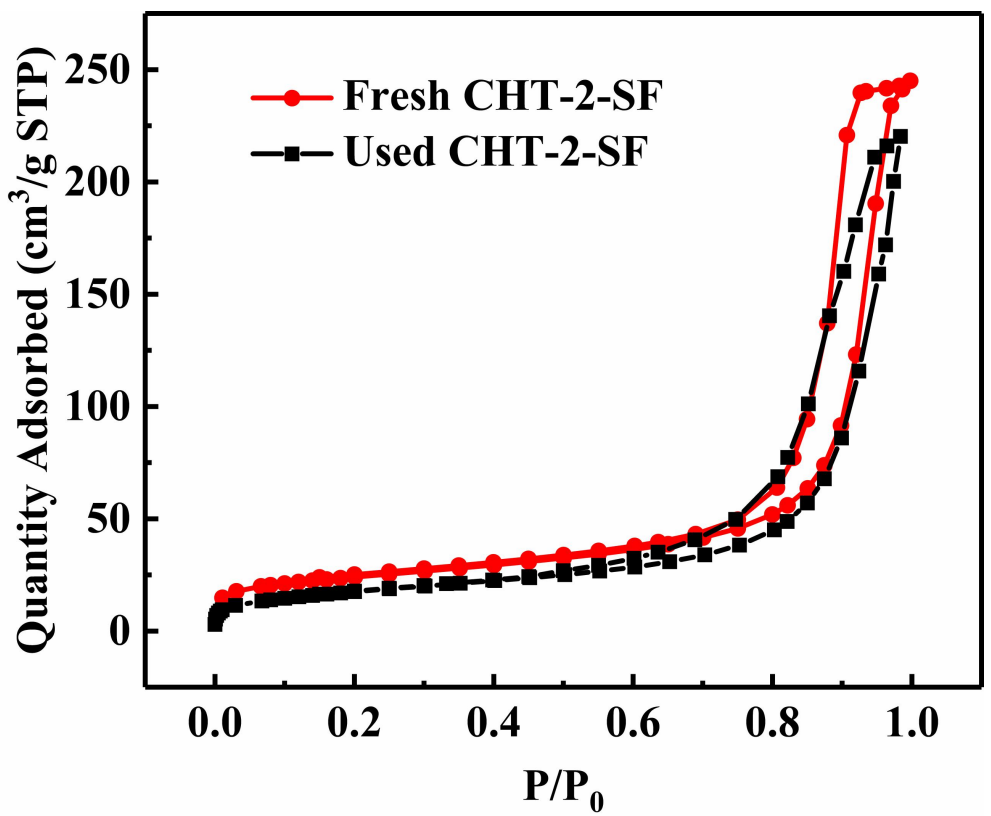

Figure S5. $\mathrm{N}_{2}$ adsorption-desorption isotherms of fresh and used CHT-2-SF sample. 


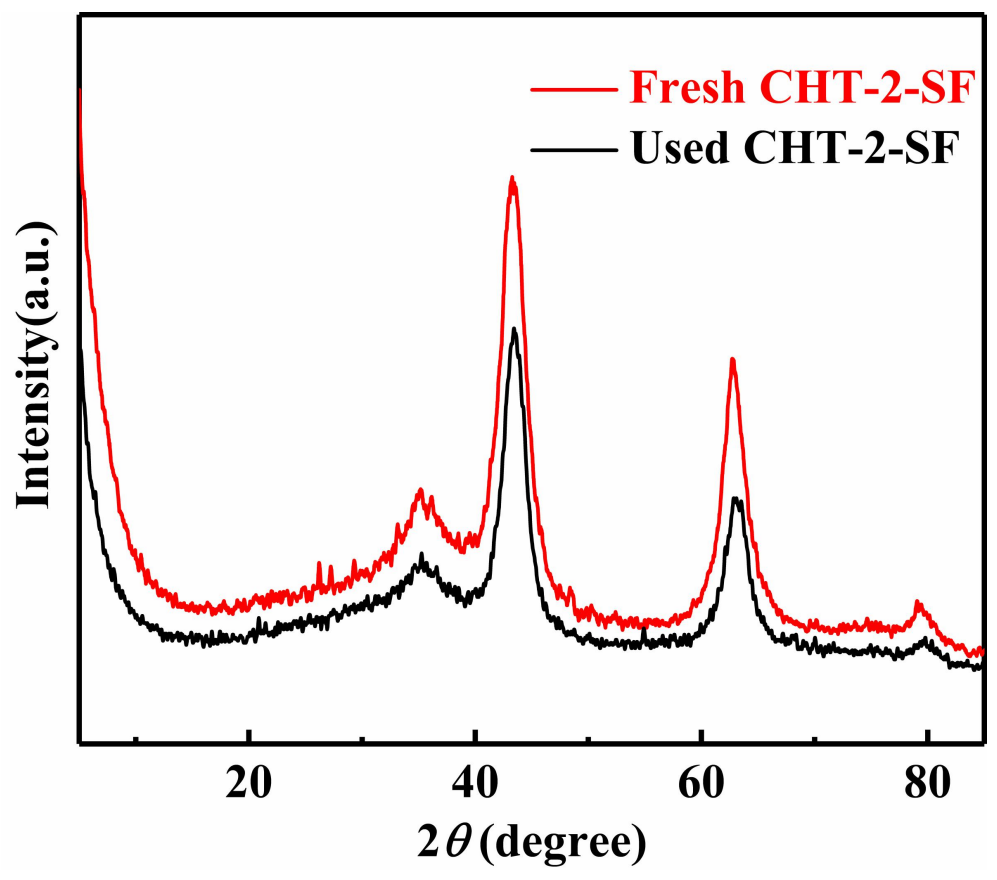

Figure S6. XRD patterns of fresh and used CHT-2-SF sample.

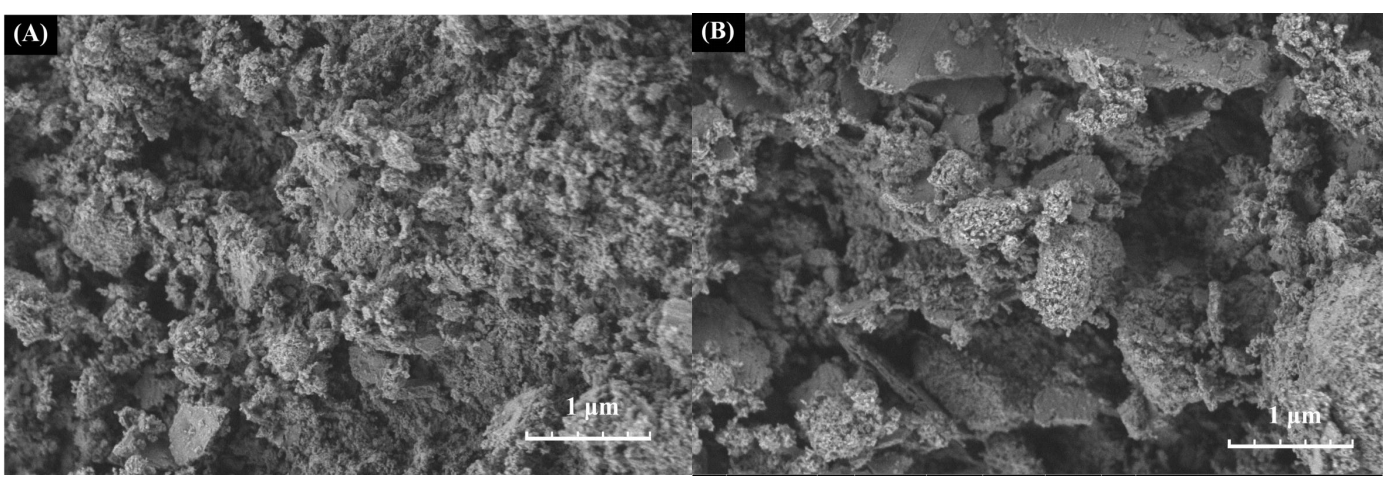

Figure S7. SEM images of (A) fresh and (B) used CHT-2-SF sample. 

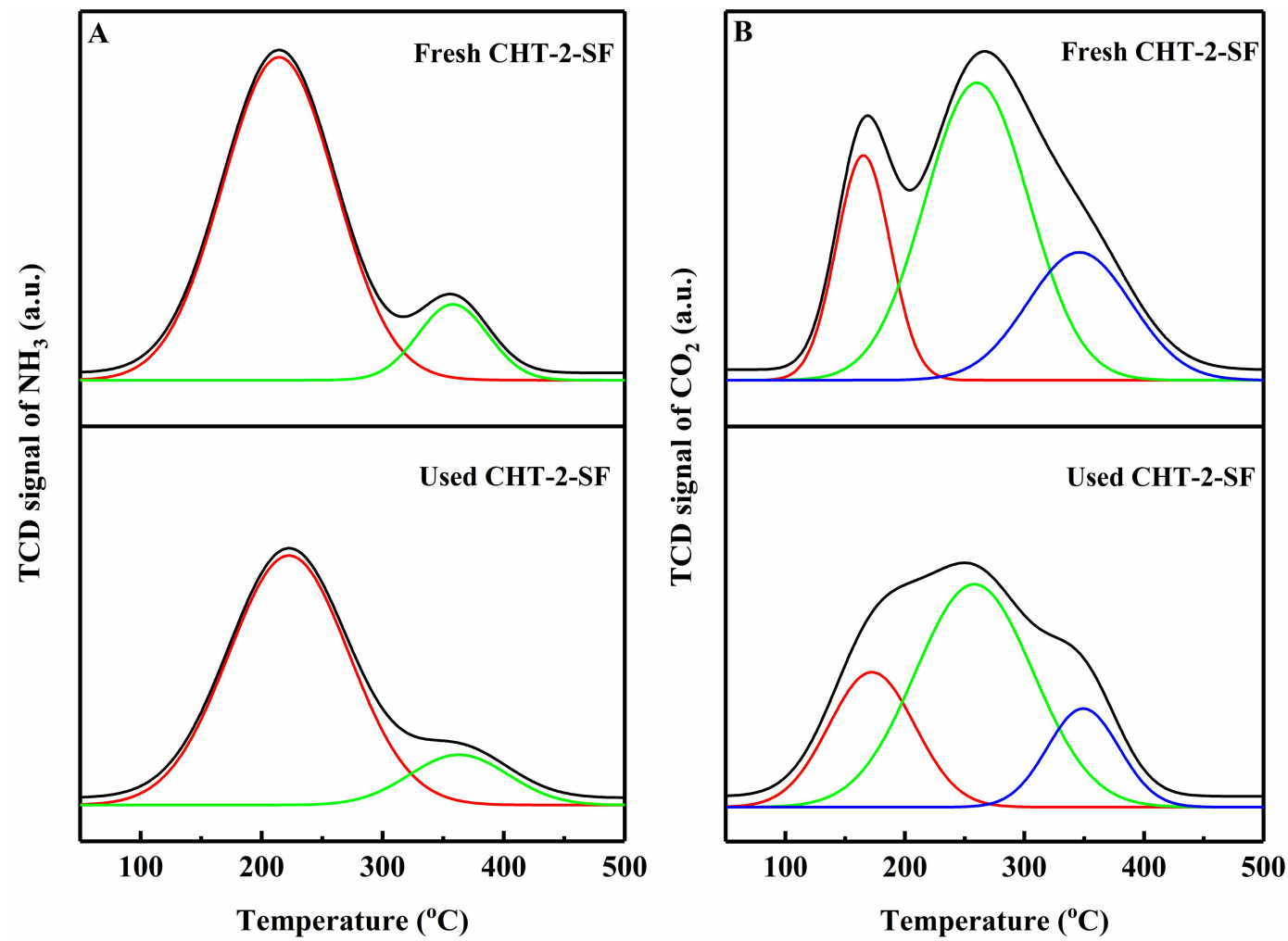

Figure S8. $\mathrm{NH}_{3}$-TPD (A) and $\mathrm{CO}_{2}$-TPD (B) of fresh and used CHT-2-SF sample. 